\title{
In Vitro Comparison of the Effectiveness of a Resin Infiltration System and a Dental Adhesive System in Dentinal Tubule Penetration
}

\author{
Esra Ozyurt ${ }^{1}$ (D), Hacer Deniz Arisu² $(\mathbb{D})$, Emin Turkoz ${ }^{2,3}$ (D) \\ ${ }^{1}$ Trakya University, Faculty of Dentistry, Department of Restorative Dentistry, Edirne, Turkey. \\ ${ }^{2}$ Gazi University ,Faculty of Dentistry, Department of Restorative Dentistry, Edirne, Turkey. \\ ${ }^{3}$ Ahmet Yesevi International Turkish-Kazakh University, Faculty of Dentistry, Turkestan, Kazakhstan (Temporarily). \\ Correspondence Author: Esra Ozyurt \\ E-mail: esraozyurt@trakya.edu.tr \\ Received: 21.05.2018 Accepted: 16.08.2018
}

\begin{abstract}
Objective: The aim of this study was to assess and compare the dentin tubule penetration effectiveness of a dental adhesive and a resin infiltration system used with two different surface treatments.

Methods: Dentin specimens were obtained from 42 impacted lower right wisdom tooth, 2 of these specimens were used to detect the effects of surface treatments. Two different surface treatments (37\% phosphoric acid and 17\% EDTA) were applied to the samples to compare the dentin tubule penetration effectiveness of a dental adhesive -which had been using for treatment of dentin hypersensitivity - and a resin infiltration system. Scanning electron microscopy was used to investigate the tubule penetration effectiveness. For statistical analysis, Kruskal Wallis and Mann Whitney $U$ and One Way Analysis of Variance (ANOVA) and Tukey HSD tests were used.

Results: ICON had shown significantly more resin penetration intensity and more resin penetration depth than Adper Single Bond 2 ( $p<0.05$ ). Phosphoric acid treatment groups had shown significantly more penetration intensity than EDTA treated groups $(p=0.001)$.

Conclusion: According to the results of this study, it can be concluded that tubuler penetration effectivenes of ICON resin infiltration system is better than Adper Single Bond 2 adhesive system.

Keywords: Dentin sensitivity, resins, adhesives, microscopy
\end{abstract}

\section{INTRODUCTION}

Dentin hypersensitivity is defined as a "short, sharp pain arising from exposed dentin in response to thermal, evaporative, tactile, osmotic or chemical stimuli" (1-5). For dentin sensitivity to develop, the dentinal tubules leading from the dentin surface to the pulp must be open (2).

A number of theories have been used to explain dentinal hypersensitivity. The most widely accepted mechanism is described by the "Hydrodynamic theory," proposed by Branstrom and Astron in 1964 (5-7).

Two basic approaches are used to treat dentin hypersensitivity. The first is to occlude dentinal tubules, preventing the disturbance of hydrodynamic fluid and blocking neural transmission in the pulp $(8,9)$. This approach involves filling the dentinal tubules or forming a precipitate on their surfaces (10). Because the agents used to treat sensitivity generate a superficial precipitate on the tubules' surface, no single desensitizing agent is considered ideal for managing dentin hypersensitivity $(5,10-13)$.

Infiltration resins are generally recently developed materials that are used to treat early enamel lesions (caries) and white spot caries-like lesions. These materials can effectively penetrate the enamel $(14,15)$. The purpose of this study was to investigate the effectiveness of resin infiltration in occluding tubules and treating dentin hypersensitivity by assessing the penetration of resin into dentinal tubules.

In this study, scanning electron microscopy (SEM) was used to compare the dentinal tubule penetration of a dentin hypersensitivity dental adhesive treatment with that of a resin infiltration system. These treatments were combined with two dentin surface pre-treatments, 37\% phosphoric acid and $17 \%$ ethylenediaminetetraacetic acid (EDTA).

Two null hypotheses were tested. The first null hypothesis was that the surface pre-treatments would have no effect on resin penetration. The second null hypothesis was that triethyleneglycol dimethacrylate (TEGDMA) containing the resin infiltration system and bisphenylglycidyl dimethacrylate (BisGMA) containing the adhesive system would show similar levels of penetration.

\section{METHODS}

This study used 42 impacted caries-free human third molar teeth and a protocol approved by the ethics committee with the No. 36290600/03. The teeth were obtained from 
individuals aged 23-30 years. Teeth that had been cracked or damaged during extraction were excluded. Only teeth extracted within 1 month prior to the study were used and these were stored in distilled water. A microtome was used to cut the teeth at their roots $3 \mathrm{~mm}$ below the enamelcement junction. The pulp was removed using an excavator. The buccal enamel layer, cement, and superficial dentin were removed using a drill, and the prepared surfaces were polished using 320, 400,600, 800, and 1000 grit abrasives, all while cooling the samples with water. The cervical dentin surfaces were examined and the samples stored in distilled water before the treatments were performed. The samples were dried with a gentle stream of air and randomly divided into two groups, each of which was then divided into two subgroups $(n=10)$. To visualize the tubular openings, a dentin sample from each subgroup was treated with $17 \%$ EDTA for $1 \mathrm{~min}$ and $37 \%$ phosphoric acid for $15 \mathrm{~s}$ and examined using SEM. The materials used in the study are listed in Table 1.

Table 1. The materials and product details used in the study.

\begin{tabular}{|c|c|c|}
\hline $\begin{array}{l}\text { Material } \\
\text { (Manufacturer) }\end{array}$ & Application Technique & Composition \\
\hline $\begin{array}{l}\text { ICON Dry } \\
\text { (DMG, Hamburg, } \\
\text { Germany) }\end{array}$ & $\begin{array}{l}\text { Apply the etched enamel surface } \\
\text { and set for } 30 \text { seconds. Dry with } \\
\text { oil-free and water-free air. }\end{array}$ & \%99 Ethanol \\
\hline $\begin{array}{l}\text { ICON Infiltrant } \\
\text { (DMG, Hamburg, } \\
\text { Germany) }\end{array}$ & $\begin{array}{l}\text { Apply an ample amount of Icon- } \\
\text { Infiltrant onto the etched surface } \\
\text { by turning the shaft and set for } 3 \\
\text { minutes. Remove excess material } \\
\text { with a cotton roll and dental floss. } \\
\text { Light-cure Icon-Infiltrant for } 40 \\
\text { seconds. Repeat the application } \\
\text { and set for } 1 \text { minute. Remove } \\
\text { excess material and light-cure for a } \\
\text { minimum of } 40 \text { seconds. }\end{array}$ & $\begin{array}{l}\text { TEGDMA-based } \\
\text { resin, initiators } \\
\text { and stabilizers }\end{array}$ \\
\hline $\begin{array}{l}\text { Adper Single } \\
\text { Bond } 2 \\
\text { (3M ESPE, } \\
\text { Germany) }\end{array}$ & $\begin{array}{l}\text { 3. for } 10 \text { sec onds } \\
\text { Apply etchant for } 15 \text { seconds. } \\
\text { Rinse for } 10 \text { seconds. Blot excess } \\
\text { water using a cotton pellet or } \\
\text { mini-sponge. After blotting, apply } \\
\text { 2-3 consecutive coats of adhesive } \\
\text { for } 15 \text { seconds with gentle } \\
\text { agitation using a fully saturated } \\
\text { applicator. Gently air thin for } 5 \\
\text { seconds to evaporate solvents. } \\
\text { Light-cure for } 10 \text { seconds. }\end{array}$ & $\begin{array}{l}\text { Bis-GMA, HEMA, } \\
\text { dimethacrylates, } \\
\text { ethanol, water, } \\
\text { photoinitiator, } \\
\text { methacrylate } \\
\text { functional } \\
\text { copolymer of } \\
\text { polyacrylic and } \\
\text { poly (itaconic) } \\
\text { acids, silica } \\
\text { particles } \\
\end{array}$ \\
\hline $\begin{array}{l}\text { Panora } 200 \\
\text { Phosphoric Acid } \\
\text { (Imıcryl, Konya, } \\
\text { Turkey) }\end{array}$ & $\begin{array}{l}\text { Apply dentine surface and set for } \\
15 \text { seconds. Dry with oil-free and } \\
\text { water-free air for } 10 \text { seconds. }\end{array}$ & $\begin{array}{l}\text { 37\% Phosphoric } \\
\text { Acid }\end{array}$ \\
\hline $\begin{array}{l}\text { EDTA Solution } \\
\text { (Werax, Turkey) }\end{array}$ & & $\begin{array}{l}17 \% \text { Ethylene } \\
\text { diamide } \\
\text { tetra acetic } \\
\text { acid, sodyum } \\
\text { hydroxide, distile } \\
\text { water }\end{array}$ \\
\hline
\end{tabular}

Group 1a samples were treated using $37 \%$ phosphoric acid plus Adper Single Bond 2 (3M, Neuss, Germany). The vestibular surfaces of the samples were treated with $37 \%$ phosphoric acid to remove the smear layer. Following rinsing and air-drying, Adper Single Bond 2 was applied and the samples were light-cured for $20 \mathrm{~s}$, in accordance with the manufacturer's instructions.

Group 1b samples were treated using 17\% EDTA plus Adper Single Bond 2. The vestibular surfaces of the samples were treated with $17 \%$ EDTA for $60 \mathrm{~s}$ to remove the smear layer. Following rinsing and air drying, Adper Single Bond 2 was applied and the samples were light-cured for $20 \mathrm{~s}$, in accordance with the manufacturer's instructions.

Group 2a samples were treated using 37\% phosphoric acid plus Icon (DMG, Hamburg, Germany). The sample surfaces were treated with $37 \%$ phosphoric acid for $15 \mathrm{~s}$. The samples were then treated using Icon Dry and allowed to stand for $30 \mathrm{~s}$, prior to air-drying for $5 \mathrm{~s}$. The resin was applied using a circular motion to the sample surfaces for a duration of $3 \mathrm{~min}$. A gentle stream of air was applied for $5 \mathrm{~s}$ and the samples were light-cured for $40 \mathrm{~s}$. The resin was applied again for 1 min and the samples were light-cured for $40 \mathrm{~s}$.

Group 2b samples were treated using 17\% EDTA plus Icon. The vestibular surfaces of the samples were treated with $17 \%$ EDTA for $60 \mathrm{~s}$ to remove the smear layer. Icon resin was then applied using the procedure described for group 2 a samples.

All of the prepared samples were incubated in distilled water for $24 \mathrm{~h}$ at $37^{\circ} \mathrm{C}$.

The samples were sectioned longitudinally, and each crosssection surface was treated with $37 \%$ phosphoric acid for $5 \mathrm{~s}$ to remove the smear layer that had formed during sectioning. Samples were then treated with $5.25 \% \mathrm{NaOCl}$ for $3 \mathrm{~min}$ to remove all organic content. All samples were rinsed with distilled water for $1 \mathrm{~min}$, desiccated for $24 \mathrm{~h}$, and sputtercoated with gold for visualization using SEM.

A total of 80 sample surfaces were initially evaluated under low magnification. For each sample, the cervical region closest to the pulp was photographed at $700 \times$ magnification, including the treated surface. The resin density was rated by two observers who had been blinded to the treatments. The scoring system (0-3) used was described by Moradi et al. (16, 17), and the scores are defined below:

$0=$ Resin was not observed in any of the tubules examined.

$1=$ Resin was observed in less than half of the tubules examined.

$2=$ Resin was observed in more than half of the tubules examined.

$3=$ Resin was observed in all of the tubules examined.

The first eight images ( $10 \%$ of a total of 80 images) were evaluated together as part of the calibration process. The remaining images were evaluated independently. Cohen's kappa coefficient was used to assess inter-rater agreement (18). The scores assigned to the images viewed during the calibration process were not included in the kappa analysis. A consensus was reached by discussion for those images that had no inter-rater agreement. The scores determined by 
consensus were used in the statistical analyses. The greatest depth of resin penetration was measured in the region closest to the pulp in each image using the SEM device software. The scores and penetration depths were evaluated statistically.

\subsection{Statistical analysis}

The data were evaluated using SPSS (ver. 21.0; SPSS, Inc., Chicago, IL, USA). Differences in penetration densities among the groups were assessed using a Kruskal-Wallis test, and inter-group comparisons were made using a Mann-Whitney U-test. As Shapiro-Wilk test showed dependent variables were normally distributed (Table 2), one-way analysis of variance (ANOVA) and Tukey's honest significant difference (HSD) test were used to compare penetration depths. To analyze inter-group differences, $95 \%$ confidence intervals were calculated. A $p$-value $<0.05$ was considered statistically significant.

Table 2. Tests of normality for penetration depth values

\begin{tabular}{|c|c|c|c|c|c|c|c|}
\hline \multicolumn{8}{|c|}{ Tests of Normality } \\
\hline & \multirow{2}{*}{ Groups } & \multicolumn{3}{|c|}{ Kolmogorov-Smirnov ${ }^{\mathrm{a}}$} & \multicolumn{3}{|c|}{ Shapiro-Wilk } \\
\hline & & Statistic & $\mathrm{df}$ & Sig. & Statistic & $d f$ & Sig. \\
\hline \multirow{3}{*}{$\begin{array}{l}\text { Penetration } \\
\text { depth }\end{array}$} & $\begin{array}{l}\text { Phosphoric } \\
\text { Acid } \\
+ \text { +Adhesive }\end{array}$ & 173 & 20 & ,118 & ,913 & 20 & ,072 \\
\hline & $\begin{array}{l}\text { Phosphoric } \\
\text { Acid +ICON }\end{array}$ & ,124 & 20 &, $200^{*}$ & ,950 & 20 & ,369 \\
\hline & EDTA+ICON & 128 & 20 &, $200^{*}$ & ,907 & 20 &, 055 \\
\hline
\end{tabular}

$*$. This is a lower bound of the true significance, a. Lilliefors Significance Correction, b. Penetration depth is constant when Group = EDTA+Adhesive. It has been omitted.

\section{RESULTS}

The effects of the surface pre-treatments on the smear layer were evaluated in samples that were not included in the study groups. There were more open dentinal tubules in samples treated with phosphoric acid than in those treated with EDTA, as shown in Figures 1 and 2, respectively.

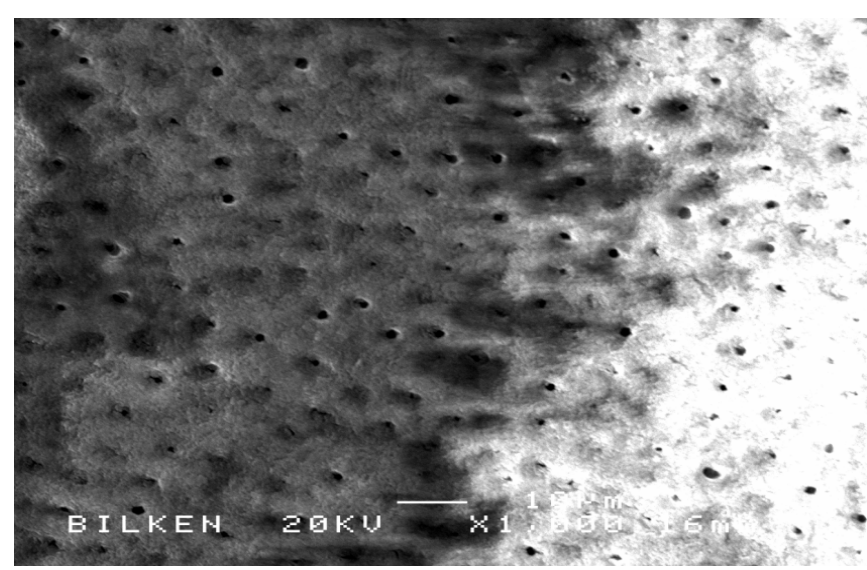

Figure 1. Image of dentin surface treated with $37 \%$ phosphoric acid

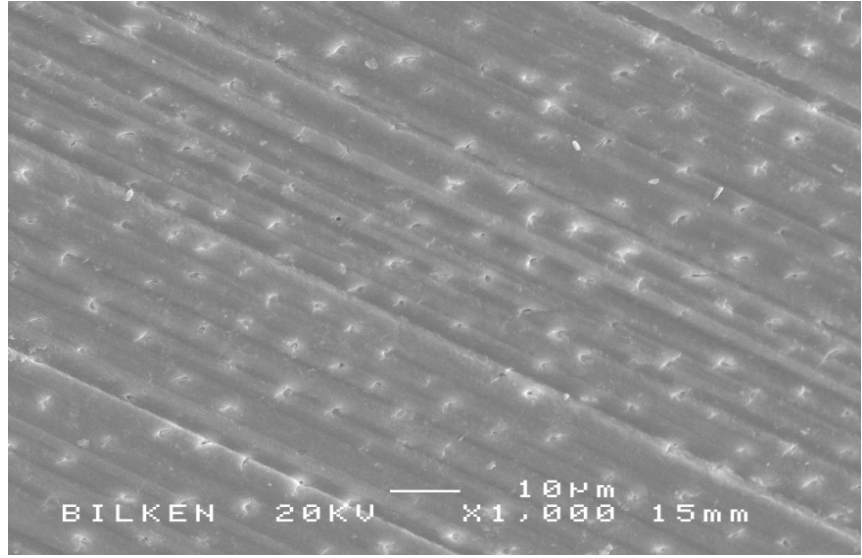

Figure 2. Image of dentin surface treated with $17 \%$ ethylenediaminetetraacetic acid (EDTA)

The kappa value for inter-rater agreement of 0.79 indicated strong agreement. Surface images at $700 \times$ magnification and penetration depth measurements from one sample in each group are shown in Figures 3-9. We did not find resin in any of the EDTA plus adhesive group sample images.

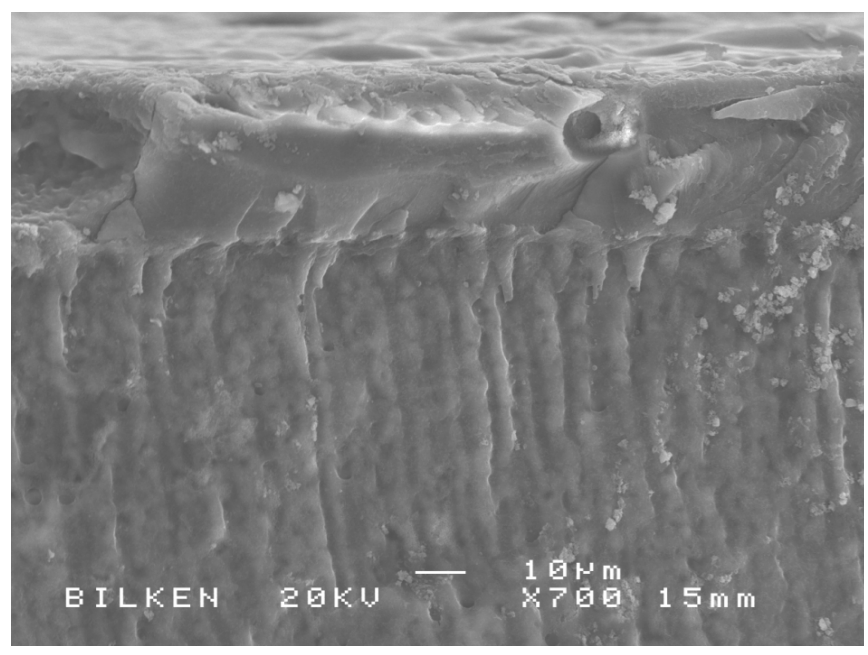

Figure 3. Scanning electron microscopy (SEM) image of a group 1 a (phosphoric acid plus adhesive) sample at 700x magnification

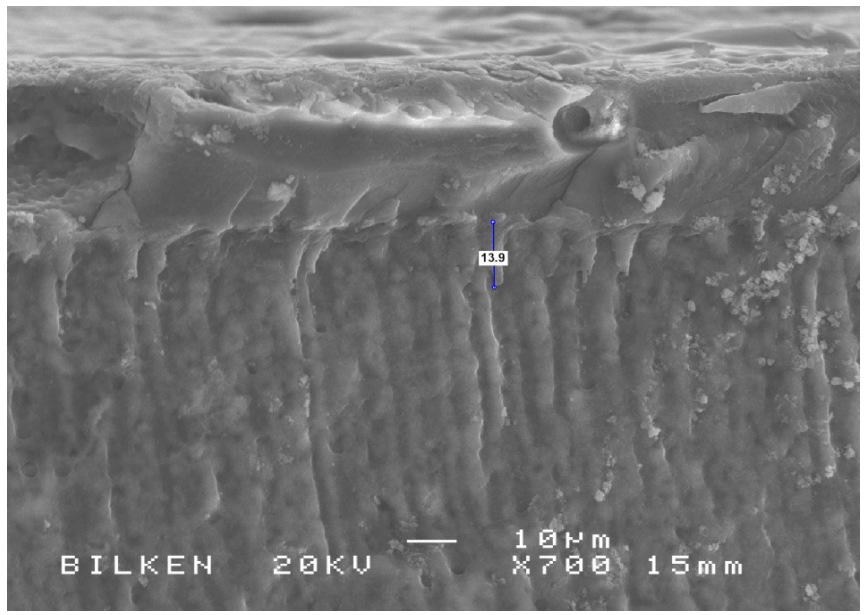

Figure 4. Penetration depth measurement in a group 1a (phosphoric acid plus adhesive) sample 


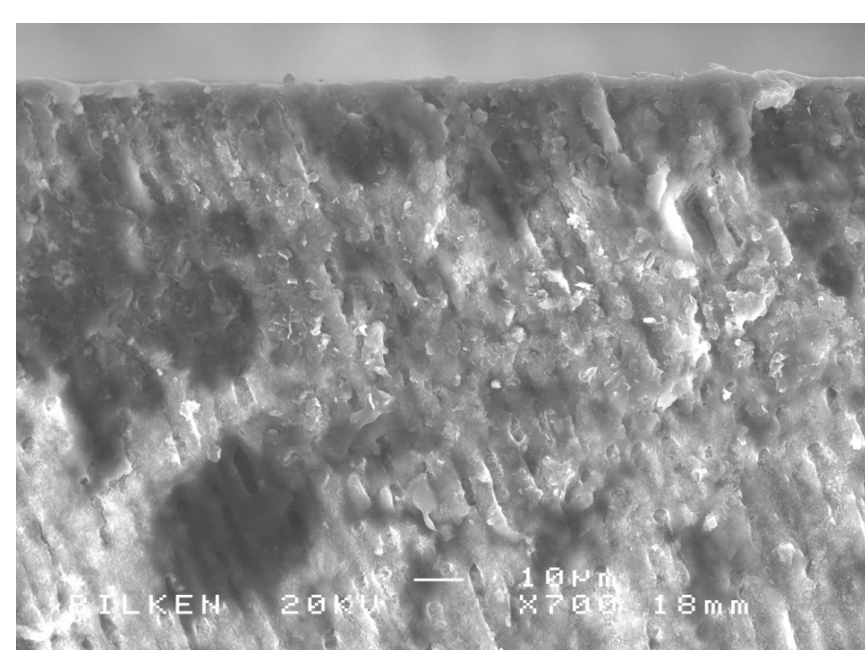

Figure 5. SEM image of a group $1 b$ (EDTA plus adhesive) sample at 700x magnification

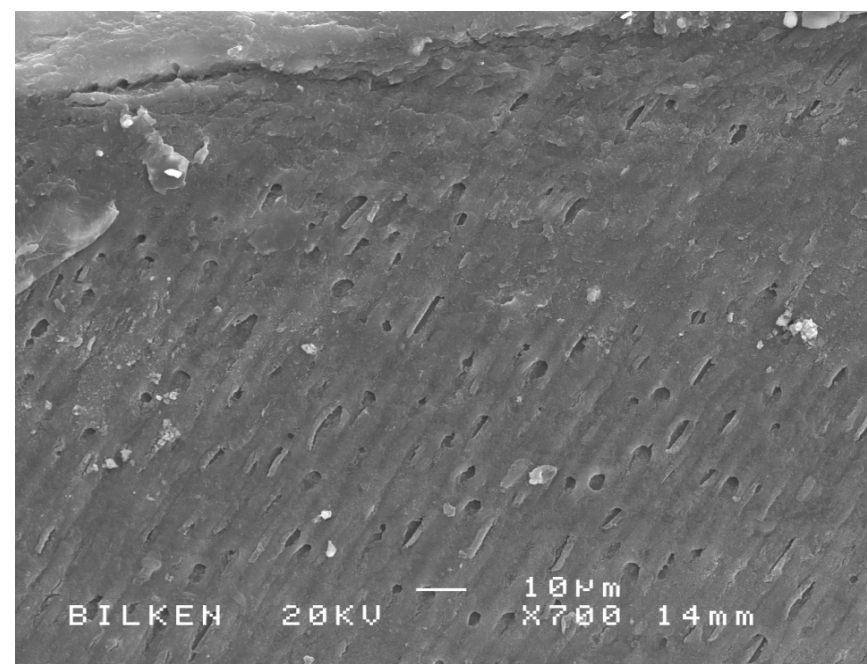

Figure 6. SEM image of a group $2 a$ (phosphoric acid plus Icon) sample at $700 \times$ magnification

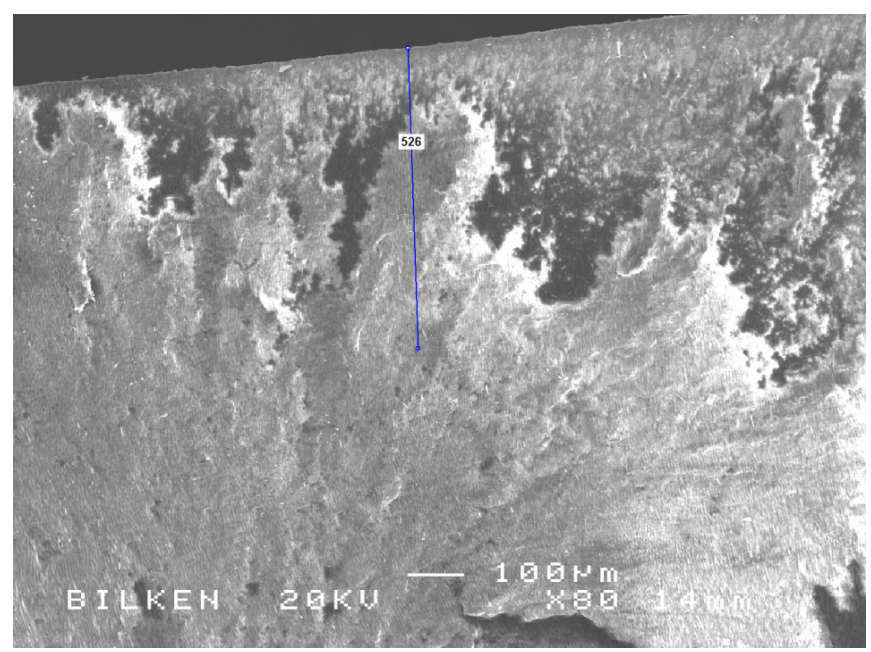

Figure 7. Penetration depth measurement in a group $2 a$ (phosphoric acid plus Icon) sample

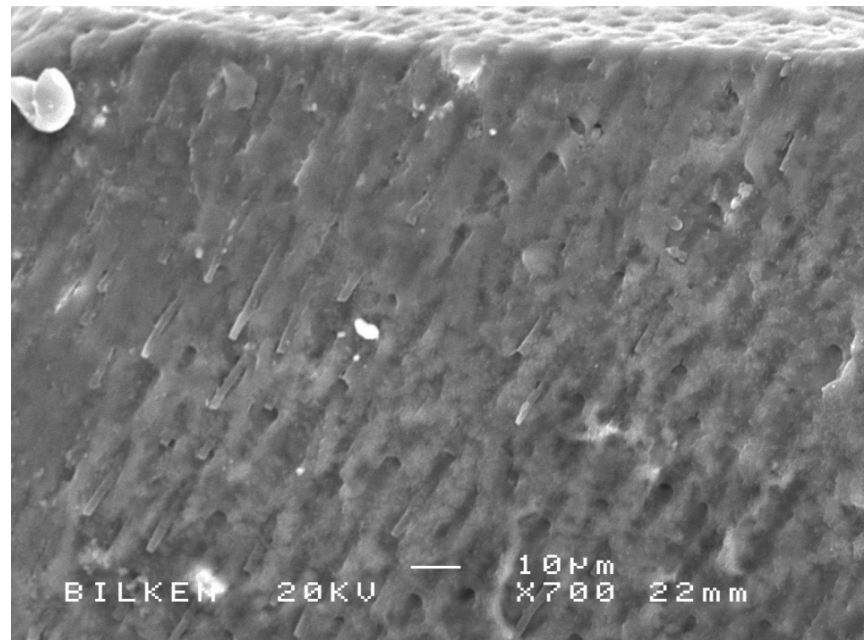

Figure 8. SEM image of a group $2 b$ (EDTA plus Icon) sample at $700 x$ magnification

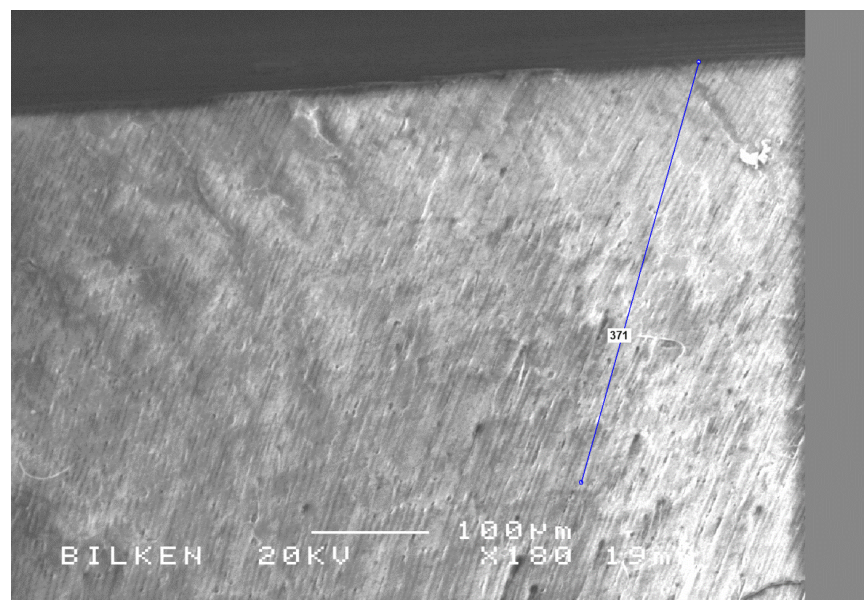

Figure 9. Penetration depth measurement in a group $2 b$ (EDTA plus Icon) sample

Comparing the penetration densities using a Kruskal-Wallis test demonstrated significant differences among the study groups $(p=0.000)$. There was a significant difference in penetration density between the phosphoric acid and EDTA surface pre-treatment groups $(p=0.001)$. Additionally, the Icon group demonstrated significantly more penetration density than did the adhesive group ( $p=0.000)$. (Table 3, Table 4$)$

Table 3. Mean ranks of study groups for penetration density

\begin{tabular}{|l|l|l|}
\hline Groups & N & Mean Rank \\
\hline Group 1a (Phosphoric Acid+Adhesive) & 20 & 35,60 \\
\hline Group 1b (EDTA+Adhesive) & 20 & 12,50 \\
\hline Grup 2a (Phosphoric Acid+ICON) & 20 & 61,75 \\
\hline Grup 2b (EDTA+ICON) & 20 & 52,15 \\
\hline
\end{tabular}


Table 4. Test statistics of Kruskal Wallis and Mann Whitney U for penetration density

\begin{tabular}{|c|c|c|}
\hline Variable & \multicolumn{2}{|c|}{ Penetration Density } \\
\hline $\begin{array}{l}\text { Kruskal } \\
\text { Wallis }\end{array}$ & $1 a, 1 b, 2 a, 2 b^{*}$ & Chi-square $=55,325 \mathrm{df}=3$ Asymp. Sig. $=, 000$ \\
\hline $\begin{array}{l}\text { Mann } \\
\text { Whitney U }\end{array}$ & $\begin{array}{l}\text { Phosphoric } \\
\text { acid vs EDTA }\end{array}$ & $U=473,000 \mathrm{Z}=-3.256$ Asymp. Sig. $=, 001$ \\
\hline $\begin{array}{l}\text { Mann } \\
\text { Whitney U }\end{array}$ & $\begin{array}{l}\text { Adhesive vs } \\
\text { ICON }\end{array}$ & $U=142,000 \mathrm{Z}=-6,551$ Asymp. Sig. $=, 000$ \\
\hline \multirow{6}{*}{$\begin{array}{l}\text { Mann } \\
\text { Whitney U }\end{array}$} & $1 a$ vs $1 b^{*}$ & $U=40,000 \mathrm{Z}=-4,954$ Asymp. Sig. $=, 000$ \\
\hline & $1 a$ vs $2 a^{*}$ & $U=45,000 Z=-4,377$ Asymp. Sig. $=, 000$ \\
\hline & $1 \mathrm{a}$ vs $2 \mathrm{~b}^{*}$ & $U=97,000 \mathrm{Z}=-2,947$ Asymp. Sig. $=, 003$ \\
\hline & $1 b$ vs $2 a^{*}$ & $U=, 000 \mathrm{Z}=-5,888$ Asymp. Sig. $=, 000$ \\
\hline & $1 b$ vs $2 b^{*}$ & $U=, 000 \mathrm{Z}=-5,831$ Asymp. Sig. $=, 000$ \\
\hline & $2 a$ vs $2 b^{*}$ & $U=130,000 \mathrm{Z}=-2,063$ Asymp. Sig. $=, 039$ \\
\hline
\end{tabular}

*Statistically significant difference between groups

Multiple comparisons using the Mann-Whitney U-test demonstrated significant differences between penetration densities of groups $1 a$ and $1 b$, groups $1 a$ and $2 a$, groups $1 a$ and $2 b$, groups $1 b$ and $2 a$, groups $1 b$ and $2 b$, and groups $2 a$ and $2 \mathrm{~b}(p=0.000, p=0.000, p=0.003, p=0.000, p=0.000$, and $p=0.039$, respectively). (Table 4 )

The mean and standard deviation for penetration depts of each group is listed in Table 5. The results of the multiple inter-group penetration depth comparisons are shown in Table 6. Group 2a samples had the deepest level of resin penetration, followed by group $2 b$, group $1 a$, and group $1 b$, in decreasing order.

Table 5. Mean and standard deviation values of penetration depths

\begin{tabular}{|l|l|l|l|l|l|l|}
\hline & N & Mean & $\begin{array}{c}\text { Std. } \\
\text { Deviation }\end{array}$ & Std. Error & \multicolumn{2}{|c|}{$\begin{array}{c}95 \% \\
\text { Confidence } \\
\text { Interval for } \\
\text { Mean }\end{array}$} \\
\cline { 3 - 7 } & & & & $\begin{array}{c}\text { Lower } \\
\text { Bound }\end{array}$ & $\begin{array}{c}\text { Upper } \\
\text { Bound }\end{array}$ \\
\hline $\begin{array}{l}\text { Group 1a } \\
\text { (Phosphoric } \\
\text { Acid+Adhesive) }\end{array}$ & 20 & 15,685 & 10,9048 & 2,4384 &, 0 & 42,3 \\
\hline $\begin{array}{l}\text { Group 1b } \\
\text { (EDTA+Adhesive) }\end{array}$ & 20 &, 000 &, 0000 &, 0000 &, 0 &, 0 \\
\hline $\begin{array}{l}\text { Grup 2a } \\
\text { (Phosphoric } \\
\text { Acid+ICON) }\end{array}$ & 20 & 818,950 & 396,8596 & 88,7405 & 201,0 & 1461,0 \\
\hline $\begin{array}{l}\text { Grup 2b } \\
\text { (EDTA+ICON) }\end{array}$ & 20 & 621,750 & 294,6923 & 65,8952 & 269,0 & 1384,0 \\
\hline Total & 80 & 364,096 & 438,4873 & 49,0244 &, 0 & 1461,0 \\
\hline
\end{tabular}

*The mean difference is significant at the 0.05 level.
Table 6. Tukey's honest significant difference results for the multiple inter-group comparisons among the penetration depth results

\begin{tabular}{|c|c|c|c|c|}
\hline & (J) Groups & $\begin{array}{l}\text { Mean } \\
\text { Difference } \\
(I-J)\end{array}$ & Std. Error & Sig. \\
\hline \multirow{3}{*}{$\begin{array}{l}\text { Phosphoric } \\
\text { Acid+Adhesive }\end{array}$} & EDTA+Adhesive & 15,68500 & 78,17608 & ,997 \\
\hline & $\begin{array}{l}\text { Phosphoric Acid } \\
+ \text { ICON }\end{array}$ & $-808,26500 *$ & 78,17608 & ,000 \\
\hline & EDTA+ICON & $606,06500 *$ & 78,17608 &, 000 \\
\hline \multirow{3}{*}{ EDTA+Adhesive } & $\begin{array}{l}\text { Phosphoric Acid } \\
\text { +Adhesive }\end{array}$ & $-15,68500$ & 78,17608 & ,997 \\
\hline & $\begin{array}{l}\text { Phosphoric Acid } \\
+ \text { ICON }\end{array}$ & $818,95000^{*}$ & 78,17608 & ,000 \\
\hline & EDTA+ICON & $-621,75000^{*}$ & 78,17608 &, 000 \\
\hline \multirow{3}{*}{$\begin{array}{l}\text { Phosphoric } \\
\text { acid+ICON }\end{array}$} & $\begin{array}{l}\text { Phosphoric Acid } \\
\text { +Adhesive }\end{array}$ & $803,26500^{*}$ & 78,17608 & , 000 \\
\hline & EDTA+Adhesive & $818,95000^{*}$ & 78,17608 &, 000 \\
\hline & EDTA+ICON & 197,20000 & 78,17608 & ,064 \\
\hline \multirow{3}{*}{ EDTA+ICON } & $\begin{array}{l}\text { Phosphoric Acid } \\
\text { +Adhesive }\end{array}$ & $606,06500^{*}$ & 78,17608 &, 000 \\
\hline & EDTA+Adhesive & 621,75000* & 78,17608 & , 000 \\
\hline & $\begin{array}{l}\text { Phosphoric Acid } \\
+ \text { ICON }\end{array}$ & $-197,20000$ & 78,17608 & ,064 \\
\hline
\end{tabular}

*The mean difference is significant at the 0.05 level.

Tukey's HSD test showed there was no significant difference between the penetration depth values in the phosphoric acid plus adhesive group and the EDTA plus adhesive group samples $(p=0.997)$. Similarly, there was no significant difference between the penetration depth values in the phosphoric acid plus Icon group and the EDTA plus Icon group samples $(p=0.064)$. There were statistically significant differences among all other groups $(p<0.05)$.

When all the surface treatments were compared, the samples in groups pre-treated with phosphoric acid showed deeper penetration, but the differences between these samples and those in the groups pre-treated with EDTA were not statistically significant $(p=0.280)$.

The Icon group samples showed a significantly deeper level of penetration than the adhesive group samples $(p=0.000)$.

\section{DISCUSSION}

In this study, the penetration of a highly effective enamel infiltration resin and an adhesive system used in sensitivity treatment were compared using different surface pretreatment procedures $(14,15)$. The Icon manufacturer's instructions recommend removing the hyper-mineralized layer on the surface of the tooth enamel with $\mathrm{HCl}$. However, due to the differences in the enamel and dentin mineral content, the cellular structure of dentin, the risk of pulpal inflammation, and the lack of reports in the literature describing $\mathrm{HCl}$ application to the surface of dentin at different concentrations and for different durations, we did not use $\mathrm{HCl}$. Instead, we used phosphoric acid and EDTA for dentin surface pre-treatments.

EDTA is usually applied clinically at a concentration of 15$17 \%$ and can remove the smear layer in less than $1 \mathrm{~min}(19)$. 
We looked at the smear removal procedures used in similar studies and decided to apply $17 \%$ EDTA solution to the dentin surface for $1 \mathrm{~min}$ in our study (20).

Ersöz and Özyurt described how 37\% phosphoric acid removed tubular plugs and peritubular dentin in addition to removing the smear layer on the surface of dentin; the openings became significantly wider and funnel-shaped after they were emptied (21). In our study, the samples pre-treated with phosphoric acid showed more extensive and deeper resin penetration. SEM images showed that the application of $17 \%$ EDTA for 1 min did not widen the tubules sufficiently to allow resin infiltration. These results demonstrate that at the concentrations and durations used in this study, phosphoric acid is more effective than EDTA for removing the superficial smear layer. Therefore, the first null hypothesis, which states that the different surface pre-treatments would not affect resin penetration can be rejected.

Sauro et al. investigated the application of similar experimental adhesives to dentin samples pre-treated with either 5\% EDTA or phosphoric acid and found that the resins infiltrated a smaller area in EDTA-treated samples compared with those treated using phosphoric acid (22).

To optimize the penetration of hydrophobic monomers (e.g., BisGMA), the collagen matrix in the demineralized dentin may be treated with ethanol rather than water. This is the basis of the ethanol-wet bonding technique (23). As a result, the acidified collagen matrix may be less hydrophilic and phase separation of hydrophobic monomers may be prevented (24). Following the surface pre-treatment procedures, we applied a primer containing $99 \%$ ethanol to the surfaces of samples to be treated with Icon, in accordance with the manufacturer's instructions. It is likely that this ethanol-wet bonding step used in our study enhanced resin penetration in the samples treated with Icon.

In their sensitivity treatment study, Ünlü and Bala concluded that the inclusion of both water and ethanol as solvents in Single Bond enhanced the material's properties (25). They also said that the presence of hydroxyethyl methacrylate (HEMA) may have meant that the dentinal tubules were blocked more effectively by the Single Bond reagent. However, Ünlü and Bala also described how many of their patients' tooth-sensitivity problems recurred (25). This suggests that adhesives may not be ideal for long-term sensitivity treatment. It is likely that this long-term failure in sensitivity treatment is due to superficial blocking of the dentinal tubules that is subsequently reversed by brushing or dietary acid $(5,11-13)$. Therefore, although ethanol and HEMA may be effective in treating short-term dentin sensitivity, they are not sufficient for successful treatment in the long term. The depth of resin penetration may be insufficient.

The BisGMA monomer is one of the main monomers used in adhesive dentistry and is highly viscous (26). The lowviscosity reagent TEGDMA is added to dilute viscous resins, enhancing their infiltration capacity $(27,28)$. In this study, we compared the penetration of an adhesive containing BisGMA with Icon containing TEGDMA. Statistical analysis showed there were significant differences among all groups $(p<0.05)$. Resin penetration was most effective in the phosphoric acid plus Icon group samples, probably due to the highly effective penetration properties of TEGDMA. This was followed by the EDTA plus Icon group samples, the phosphoric acid plus adhesive group, and the EDTA plus adhesive group samples, all in decreasing order of penetration. We found that the Icon resin infiltrated samples in both surface pretreatment groups more effectively than did the Adper Single Bond 2 reagent. This is probably because Icon contains TEGDMA, which has a higher penetration coefficient than the combination of HEMA and ethanol present in Adper Single Bond 2. Penetration depth of resin may also be affected by viscosity of the materials used. Adper Single Bond 2, is a filled adhesive resin with low viscosity. The size of the fillers are approximately $5 \mathrm{~nm}$ (29) but it was proved that these small nanofillers could not penetrate into the interfibrillar space of $20 \mathrm{~nm}$ to form the hybrid layer $(30,31)$. In an in vitro study, Araújo et al. revealed that addition of hydrophobic monomers and solvents (mainly ethanol) into TEGMA blends resulted in decreased penetration depth (32). Altohugh all materials used in this study are manufacturing as low viscosity materials, our results could be attributed to their different monomer and solvent compositions.

The resin penetration depth measurements demonstrated that the phosphoric acid plus Icon group samples showed the deepest penetration, followed by the EDTA plus Icon, and phosphoric acid plus adhesive group samples, in decreasing order. No resin penetration was found in the EDTA plus adhesive group samples. Therefore, the second null hypothesis, which states that Icon and Adper Single Bond 2 would show similar levels of dentin penetration was also rejected.

Griffiths et al. investigated adhesives containing different monomers on dentin pre-treated with phosphoric acid and found that the resin penetrated deeper when the adhesive contained TEGDMA compared with other adhesives (33). We demonstrated that Icon containing TEGDMA penetrated dentin deeper and more effectively than did Adper Single Bond 2 containing BisGMA and HEMA, in samples that had been pre-treated with phosphoric acid.

TEGDMA has a low degree of monomer conversion and when it penetrates parts of the tooth close to the pulp there is a risk of adverse outcomes, including pulpal inflammation and necrosis (28). TEGDMA is typically applied to the enamel surface; toxicity studies will be required to evaluate its safety for use in the cervical region or near the pulp. In addition to assessing the depths of penetration investigated here, more comprehensive studies should also be performed to investigate how effectively these reagents block dentinal tubules. The limitation of this study was to evaluate the penetration with a 2D SEM image. It could be insufficiant to give precise results and further studies are needed to evalute the penetration in 3D manner. 


\section{CONCLUSION}

Within the limitations of this in vitro study we concluded the following. For removing the superficial smear layer, treatment with $37 \%$ phosphoric acid for $15 \mathrm{~s}$ is more effective than treatment with $17 \%$ EDTA for $1 \mathrm{~min}$. The Icon resin infiltration system penetrates dentinal tubules more effectively than does the adhesive system tested. Treatment of dentinal hypersensitivity is an area of active research and more in vitro, in vivo, and clinical follow-up studies will be required to determine the ideal treatment materials and methods.

Acknowledgements: The authors are thankful to Professor Atila Aydinli and Murat Gure for SEM examination.

\section{REFERENCES}

[1] Addy M. Dentine hypersensitivity: new perspectives on an old problem. Int Dent J 2002;52(5):367-375.

[2] Addy M, Dowell P. Dentine hypersensitivity-a review. Clinical and in vitro evaluation of treatment agents. J Clin Periodontol 1983;10(4):351-363.

[3] Brookfield JR, Addy M, Alexander DC, Benhamou V, Dolman B, Gagnon V, Gill KTS, Goulding MJ, Mackie S, Maillet WA, Schwartz $G$, Tenenbaum HC. Consensus-based recommendations for the diagnosis and management of dentin hypersensitivity. J Can Dent Assoc 2003;69(4):221-226.

[4] Pashley DH. How can sensitive dentine become hypersensitive and can it be reversed? J Dent 2013;41:49-55.

[5] Porto IC, Andrade AK, Montes MA. Diagnosis and treatment of dentinal hypersensitivity. J Oral Sci 2009;51(3):323-332.

[6] Addy M, Pearce N. Aetiological, predisposing and environmental factors in dentine hypersensitivity. Arch Oral Biol 1994;39 Suppl:33-38.

[7] Kemaloglu H, Turkun LS. Dentin hypersensitivity-physiology Turkiye Klinikleri J Res Dent - Special Topics 2015;1(1):8-15.

[8] Bamise CT, Esan TA. Mechanisms and treatment approaches of dentine hypersensitivity: a literature review. Oral Health Prev Dent 2011;9(4): 353-367.

[9] Yilmaz HG, Bayindir H, Cengiz E, Berberoglu A. Dentin hypersensitivity and treatment methods Cumhuriyet Dent $J$ 2012;15(1):71-82.

[10] Orchardson R, Gillam DG. Managing dentin hypersensitivity. J Am Dent Assoc 2006;137(7):990-8; quiz 1028-1029.

[11] Bartold PM. Dentinal hypersensitivity: a review. Aust Dent J 2006;51(3):212-218.

[12] Corona SAM, Do Nascimento TN, Catirse ABE, Lizarelli RFZ, Dinelli W, Palma-DIBB RG. Clinical evaluation of low-level laser therapy and fluoride varnish for treating cervical dentinal hypersensitivity. J Oral Rehabil 2003;30(12):1183-1189.

[13] Markowitz K, Pashley DH. Discovering new treatments for sensitive teeth: the long path from biology to therapy. J Oral Rehabil 2008;35(4):300-315.

[14] Askar H, Lausch J, Dorfer CE, Meyer-Lueckel H, Paris S. Penetration of micro-filled infiltrant resins into artificial caries lesions. J Dent 2015;43(7):832-838.

[15] Gelani R, Zandona AF, Lippert F, Kamocka MM, Eckert G. In Vitro Progression of artificial white spot lesions sealed with an infiltrant resin. Oper Dent 2014;39(5):481-488.
[16] Cal-Neto JP, de Miranda MS, Dias KR. Comparative SEM evaluation of penetration of adhesive systems in human dentin with a non-rinse conditioner and a self-etching primer. Braz Dent J 2004;15(1):19-25.

[17] Moradi S, Ghoddusi J, Forghani M. Evaluation of dentinal tubule penetration after the use of dentin bonding agent as a root canal sealer. J Endodont 2009;35(11):1563-1566.

[18] Landis JR, Koch GG. The measurement of observer agreement for categorical data. Biometrics 1977;33(1):159-174.

[19] Calt S, Serper A. Time-dependent effects of EDTA on dentin structures. J Endodont 2002;28(1):17-19.

[20] Pereira JC, Segala AD, Gillam DG. Effect of desensitizing agents on the hydraulic conductance of human dentin subjected to different surface pre-treatments-an in vitro study. Dent Mater 2005;21(2):129-138.

[21] Ersöz E, Özyurt P. The effect of various acids in different concentrationson the dentin surface: a sem study. Turkiye Klinikleri J Dental Sci 1999;5(1):55-59.

[22] Sauro S, Toledano M, Aguilera FS, Mannocci F, Pashley DH, Tay FR, Watson TF, Osorio R. Resin-dentin bonds to EDTA treated vs. acid-etched dentin using ethanol wet-bonding. Dent Mater 2010;26(4):368-379.

[23] Sancaklı HŞ. Dentin bonding systems and hybridization. J Istanb Univ Fac Dent 2010;44(3):189.

[24] Wang Y, Spencer P. Hybridization efficiency of the adhesive/dentin interface with wet bonding. J Dent Res 2003;82(2):141-145.

[25] Ünlü I, Bala O. The clinical evaluation of different materials used in treatment of dentin hypersensitivity. Acta Odontol Turc 2008;25(2):13.

[26] Powers JM., Sakaguchi RL, Craig RG. Craig's restorative dental materials. Philadelphia, PA: Elsevier/Mosby, 2012.

[27] Goncalves F, Kawano Y, Pfeifer C, Stansbury JW, Braga RR. Influence of BisGMA, TEGDMA, and BisEMA contents on viscosity, conversion, and flexural strength of experimental resins and composites. Eur J Oral Sci 2009;117(4):442-446.

[28] Hickel R, Dasch W, Janda R, Tyas M, Anusavice K. New direct restorative materials. Int Dent J 1998;48(1):3-16.

[29] Pongprueksa P, Kuphasuk W, Senawongse P. The elastic moduli across various types of resin/dentin interfaces. Dent Mater 2008;24(8):1102-1106.

[30] Kim JS, Cho BH, Lee IB, Um CM, Lim BS, Oh MH, Chang CG, Son $\mathrm{HH}$. Effect of the hydrophilic nanofiller loading on the mechanical properties and the microtensile bond strength of an ethanol-based one-bottle dentin adhesive. J Biomed Mater Res B Appl Biomater 2005;72(2):284-391.

[31] Tay FR, Fau MK, Pashley DH. Distribution of nanofillers from a simplified-step adhesive in acid-conditioned dentin. J Adhes Dent 1999;1(2):103-117.

[32] Araujo GS, Sfalcin RA, Araujo TG, Alonso RC, PuppinRontani RM. Evaluation of polymerization characteristics and penetration into enamel caries lesions of experimental infiltrants. J Dent 2013;41(11):1014-1019.

[33] Griffiths B, Watson T, Sherriff M. The influence of dentine bonding systems and their handling characteristics on the morphology and micropermeability of the dentine adhesive interface. J Dent 1999;27(1):63-71. 
